
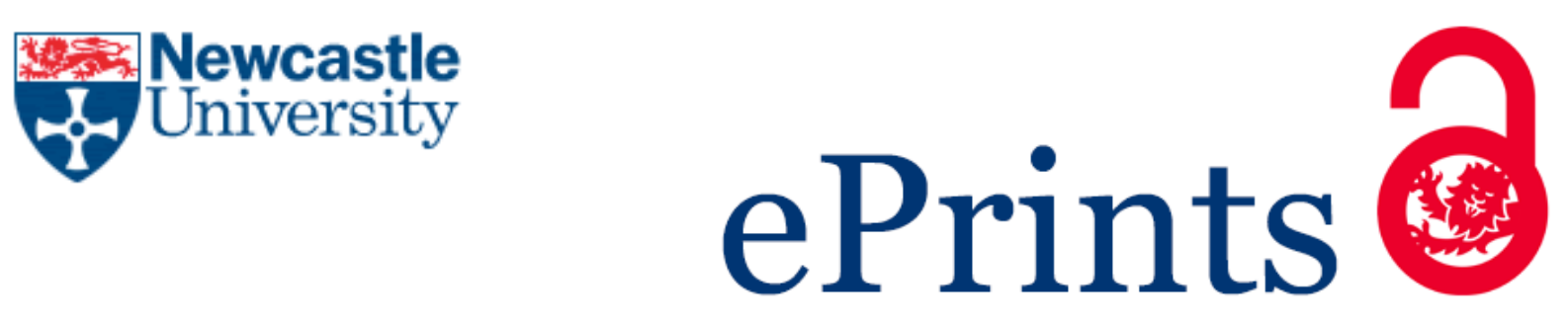

Cerff B, Maetzler W, Sulzer P, Kampmeyer M, Prinzen J, Hobert MA, Blum D, van Lummel R, Del Din S, Graeber S, Berg D, Liepelt-Scarfone I.

Home-Based Physical Behavior in Late Stage Parkinson Disease Dementia:

Differences between Cognitive Subtypes.

Neurodegenerative Diseases 2017, 17(4-5), 135-144

\title{
Copyright:
}

This is the peer-reviewed but unedited manuscript version of the following article: Cerff B, Maetzler W, Sulzer P, Kampmeyer M, Prinzen J, Hobert MA, Blum D, van Lummel R, Del Din S, Graeber S, Berg D, Liepelt-Scarfone I. Home-Based Physical Behavior in Late Stage Parkinson Disease Dementia:

Differences between Cognitive Subtypes. Neurodegenerative Diseases 2017, 17(4-5), 135-144. The final, published version is available at http://www.karger.com/10.1159/000460251

DOI link to article:

https://doi.org/10.1159/000460251

Date deposited:

03/05/2017

Embargo release date:

26 April 2018

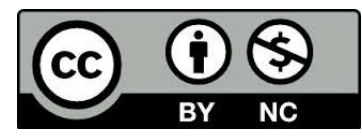

This work is licensed under a Creative Commons Attribution-NonCommercial 3.0 Unported License 


\section{Home-based physical behavior in late stage \\ 2 Parkinson's disease dementia: differences \\ 3 between cognitive subtypes}

4 Bernhard Cerff ${ }^{1,2}$, Walter Maetzler, MD ${ }^{2,4}$, Patricia Sulzer ${ }^{1,2}$, Malte Kampmeyer ${ }^{1,2}$,

5 Jos Prinzen, BEng ${ }^{5}$, Markus A. Hobert ${ }^{2,4}$, Dominik Blum, MSc ${ }^{1,2,3}$, Rob van

6 Lummel, $\mathrm{MSc}^{5}$, Silvia Del Din, $\mathrm{PhD}^{6}$, Susanne Gräber, $\mathrm{PhD}^{1,2}$, Daniela Berg,

$7 \mathrm{MD}^{2,4}$, Inga Liepelt-Scarfone ${ }^{*}, \mathrm{PhD}^{1,2}$

$9{ }^{1}$ German Center for Neurodegenerative Diseases (DZNE), University of Tübingen,

10 Tübingen, Germany, inga.liepelt@dzne.de, bernhard.cerff@student.uni-

11 tuebingen.de, Patricia.Sulzer@med.uni-tuebingen.de,

12 maltekampmeyer@hotmail.de, dominik.blum@med.uni-tuebingen.de,

13 susanne.graeber-sultan@uni-tuebingen.de

$14{ }^{2}$ Hertie Institute for Clinical Brain Research, Department of Neurodegenerative

15 Diseases, University of Tübingen, Tübingen, Germany

$16{ }^{3}$ Department of Nuclear Medicine and Clinical Molecular Imaging, University of

17 Tübingen, Germany

$18{ }^{4}$ Department of Neurology, Christian-Albrechts-University, Kiel, Germany,

19 w.maetzler@neurologie.uni-kiel.de, Markus.Hobert@uksh.de,

20 Daniela.Berg@uksh.de

$21{ }^{5}$ McRoberts B.V., The Hague, The Netherlands, J.Prinzen@mcroberts.nl,

22 rcvanlummel@mcroberts.nl

$23{ }^{6}$ Institute of Neuroscience/ Newcastle University Institute for Ageing, Clinical

24 Ageing Research Unit, Campus for Ageing and Vitality, Newcastle University,

25 Newcastle upon Tyne, UK, silvia.del-din@newcastle.ac.uk

26 Word count abstract/ main text: 248/3033

27 Number of tables/figures: $2 / 3$

28 Number of supplementary tables/figures: $1 / 1$

29 Correspondence to:

30 Inga Liepelt-Scarfone, $\mathrm{PhD}$

31 German Center of Neurodegenerative Diseases and Hertie Institute for Clinical

32 Brain Research

33 Department of Neurodegeneration

34 Hoppe-Seyler Str. 3

35 D-72076 Tuebingen, Germany

36 Tel: +4970712080424

37 Fax: +49707294490

$38 \quad$ E-Mail: inga.liepelt@dzne.de 


\section{Abstract}

2 Background: For the early diagnosis of Parkinson's disease dementia

3 (PDD), objective home-based tools are needed to quantify even mild

4 stages of activities of daily living (ADL) dysfunction.

5 Objectives: In this pilot study, home-based physical behavior was assessed

6 to examine whether it is possible to distinguish mild cognitive impairment

7 (PD-MCl) from PDD.

8 Methods: Fifty five patients with mild to severe Parkinson's disease (PD)

9 participated in this cross-sectional study. Based on comprehensive

10 neuropsychological testing, PD patients were classified as cognitively non-

11 impaired (PD-NC), PD-MCl or PDD. For physical behavior assessments,

12 patients wore the accelerometer DynaPort@ (McRoberts) for three days.

13 Ordinal logistic regression models with continuous $Y$ were applied to

14 correct results for motor impairment and depressive symptoms.

15 Results: After excluding 7 patients due to insufficient wearing time, 48

16 patients with a mean of 2 recorded days were analyzed (17 PD-NC, 22 PD-

$17 \mathrm{MCl}, 9$ PDD). ADL-impaired PDD patients showed fewer sedentary bouts

18 than non- ADL-impaired PD-MCI $[P=0.01$ odds ratio $(\mathrm{OR})=8.9,95 \%$

19 confidence interval $(\mathrm{Cl})=1.8-45.2]$ and $\mathrm{PD}-\mathrm{NC}(P=0.01, \mathrm{OR}=10.3, \mathrm{Cl}=1.6-$

20 67.3) patients, as well as a longer sedentary bout length (PD-NC: $P=0.02$,

$21 \mathrm{OR}=0.1, \mathrm{Cl}=0.02-0.65 ; \mathrm{PD}-\mathrm{MCl}: P=0.02, \mathrm{OR}=0.14, \mathrm{Cl}=0.03-0.69)$. These

22 differences were mainly caused by fewer (PD-NC: $P=0.02, \mathrm{OR}=9.6$,

$23 \mathrm{Cl}=1.5-62.4$; PD-MCl: $P=0.01, \mathrm{OR}=8.5, \mathrm{Cl}=1.5-37.3)$, but longer sitting 
1 bouts (PD-NC: $P=0.03, \mathrm{OR}=0.12, \mathrm{Cl}=0.02-0.80 ; \mathrm{PD}-\mathrm{MCl}: P=0.04$,

$2 \mathrm{OR}=0.19, \mathrm{Cl}=0.04-0.93)$. Tests assessing executive function, visuo-

3 construction and attention correlated significantly with specific activity

4 parameters (rho $\geq 0.3 ; P<0.05)$.

5 Conclusion: Objective assessment of physical behavior, in particular the

6 detection of sedentary bouts, is a promising contributor to the

7 discrimination between PD-MCl and PDD.

8 Key words: Parkinson's disease; Dementia; Physical activity; Activities of 9 daily living; Cognition; Accelerometer; Sedentary behavior. 


\section{1. Background}

2 Dementia is common in Parkinson's disease (PD) [1,2], and objective tools

3 allowing for the assessment of activities of daily living (ADL) function, and

4 thereby an early diagnosis of Parkinson's disease dementia (PDD), are

5 needed, especially as effective therapeutic options are available [3].

6 With the development of wearable and relatively unobtrusive sensor

7 systems during recent years, it has become feasible to assess home-based

8 physical behavior of PD patients over longer time periods[4], and thus

9 indirectly monitor ADL function $[5,6]$. Since ADL function is essential for the

10 discrimination of PDD from mild cognitive impairment (PD-MCl) patients

$11[7,8]$, its unbiased assessment is of utmost importance.

12 It is known that both dementia and PD are associated with reduced

13 physical activity, which can be seen even years before the diagnosis can

14 be made [9-12], yet there are few studies that investigate advanced

15 disease stages. Those few studies indicate that late stage PD patients

16 show longer bouts of sedentary behavior [13], and that energy expenditure

17 is related to cognition [14]. However, these studies excluded patients with

18 more advanced cognitive impairment $[13,14]$. To the best of our knowledge,

19 no study is currently available that has objectively assessed

20 comprehensive physical behavior parameters of PD patients with advanced

21 cognitive impairment or PDD.

22 The aim of this pilot study was to test whether objectively assessed

23 physical behavior parameters could contribute to the discrimination of 
1 cognitive subtypes of PD, especially between PDD and mild cognitive

2 impairment (PD-MCl).

\section{2. Methods}

\section{$4 \quad 2.1$ Participants}

5 A total of 55 PD patients were investigated within the frame of the

6 Dempark/Landscape study [15]. Diagnosis of PD was made according to

7 the adapted United Kingdom Parkinson's Disease Society Brain Bank

8 Criteria. Inclusion criteria included: age between 45 and 80 years, German

9 as a first language, and adequate or corrected hearing/visual abilities. The

10 following exclusion criteria were applied: history of other neurological

11 diseases affecting the central nervous system, onset of dementia within

12 one year after PD diagnosis, prior surgery due to PD, and a Mini-Mental

13 State Examination (MMSE) [16] score $<18$ points (a required cut-off, as

14 only individuals with the capacity to give informed consent could be

15 included).

16 The study was approved by the local ethical committee. All participants

17 gave written informed consent.

\section{$18 \quad 2.2$ Cognitive and motor examination}

19 Each individual underwent a clinical assessment that included the Unified

20 Parkinson Disease Rating Scale part III (UPDRS III) [17], and the Hoehn \&

21 Yahr staging scores [18]. Demographical data and medication intake was

22 also assessed. Intake of dopamimetics is expressed as the levodopa

23 equivalent daily dose (LEDD) [19]. All participants underwent a 
1 comprehensive neuropsychological assessment that included the MMSE,

2 the Parkinson Neuropsychometric Dementia Assessment (PANDA) [20],

3 and the Geriatric Depression Scale (GDS) [21], among others. Details are

4 provided in Table 1 and in the supplementary Table A.

5 Three groups were classified according to the criteria listed below: non-

6 cognitively impaired (PD-NC), for patients not meeting criteria of other

7 cognitive subtypes, PD-MCl, and PDD.

8 PD-MCl was diagnosed when the following criteria were met: (i.) one or

9 more test scores $\geq 1.5$ standard deviations below published group

10 normative values of healthy control subjects in at least one of the following

11 cognitive domains: attention, executive functions, visuo-spatial function,

12 memory, or language ability; (ii.) no significant impairment of ADL reported

13 by either the patient or the proxy; (iii.) no other primary explanations for

14 cognitive impairment or PD-associated symptoms that could significantly

15 influence cognitive testing.

16 Diagnostic criteria for PDD followed the Level-II recommendation of the

17 MDS Task Force for probable PDD [7]: (i.) At least one score $\geq 1.5$ standard

18 deviations below published group normative values of healthy control

19 subjects in at least two of the aforementioned five cognitive domains; (ii.)

20 impairment of ADL and cognitive decline with insidious onset and slow

21 progression reported by either the patient or the proxy. Details about the

22 neuropsychological assessment are provided in supplementary Table A.

232.3 Objective physical behavior assessment and parameters 
1 All participants were asked to wear the triaxial accelerometer DynaPort

2 Minimod $®$ sensor (McRoberts, The Netherlands; dimensions: $64 \times 62 \times 13$

$3 \mathrm{~mm}$ ) on their lower back for three consecutive days. Data was collected

4 with a sample frequency of $100 \mathrm{~Hz}$ and a resolution of 1 milli g-force (mg),

5 and then stored on a secure digital memory card inside the device [22].

6 Participants were asked to keep a logbook during the measurement. The

7 following time periods were documented: taking the device off (for water-

8 associated tasks), sleeping, out-of-house activities and special occasions.

9 The logbook was used for plausibility analysis in the case of irregular

10 measurements. Raw data was analyzed with algorithms provided by

11 McRoberts.

12 These algorithms differentiated the following behaviors: lying, sitting,

13 standing, walking, and shuffling (defined as an activity in upright position

14 performed with a locomotion-specific intensity, but without a locomotion-

15 specific horizontal acceleration signal) $[23,24]$. Behaviors were also

16 combined for better interpretation: (i.) sedentary combines lying and sitting;

17 (ii.) activity combines standing, shuffling and walking. Moreover, steps

18 taken during shuffling and walking were identified. Time in which the sensor

19 was not worn by the participant was detected (not-wearing time). Various

20 parameters were identified and calculated, according to the criteria listed in

21 the following sections.

\section{2.3.1 Volume}


1 Volume was defined by (i.) amount of total time spent in each behavior

2 (e.g. lying time), normalized as a percentage of 24 hours; (ii.) total number

3 of steps per day; (iii.) total amount of time spent in each intensity level

4 (defined using threshold on Metabolic Equivalent of Task category, MET)

5 normalized as a percentage of 24 hours: sedentary activity, $\leq 1.5 \mathrm{METs}$;

6 light activity, $1.5<x<3$ METs; moderate activity, $3 \leq x<6$ METs; vigorous

7 activity, $\geq 6$ METs.

$8 \quad$ 2.3.2 Pattern

9 Patterns were defined according to (i.) total number of bouts per day for

10 each behavior (e.g. number of lying bouts); (ii.) mean bout length for each

11 behavior per day (e.g. mean lying bout length), where a bout, similar to

12 other studies $[13,25]$, is defined as any period of time spent in a certain

13 behavior.

\section{$14 \quad 2.3 .3$ Intensity}

15 Intensity, as the mean vector magnitude of dynamic acceleration per day

16 for each behavior (e.g. lying intensity) or in total (total movement intensity),

17 was detected and expressed relative to gravitational acceleration by the

18 unit $\mathrm{g}\left(\mathrm{m} / \mathrm{s}^{2}\right)$.

\section{$19 \quad$ 2.3.4 Energy expenditure}

20 Energy expenditure was calculated using an algorithm based on a

21 validation study with indirect calorimetry [26] and demographic

22 characteristics of the participants. The following energy expenditure 
1 parameters were calculated: (i.) Activity related Energy Expenditure per

2 day (AEE); (ii.) Total Energy Expenditure per day (TEE); (iii.) Physical

3 Activity Level per day, as the relative energy expenditure to basal metabolic

4 rate (PAL); (iv.) Physical Activity Ratio, as the relative energy expenditure

5 to basal metabolic rate for each behavior (PAR) (e.g. PAR of lying).

\section{$6 \quad 2.4$ Data processing}

7 Criteria for data processing were as follows: days with less than 24 hours

8 recorded or with a relative wearing time $<80 \%$ of 24 hours were excluded.

9 Since no imputation [27] was applied, all results exclude the not-wearing

10 time.

\section{$11 \quad 2.5$ Statistical Analysis}

12 Values are reported as median and range. For demographical and clinical

13 variables, Kruskal-Wallis Test or Chi-square statistics were used. To adjust

14 the physical behavior parameter outcomes for motor disability and

15 depressive symptoms, ordinal logistic regression models for continuous $Y$

16 [28] were applied. Each physical behavior parameter was chosen as the

17 dependent variable, whereas group membership (coded as a dummy

18 variable) and co-variates were included as independent variables, to

19 correct for the confounders GDS and the UPDRS III score (see Table 1 for

20 details). The odds ratio (OR) with its confidence interval of $95 \%(\mathrm{Cl})$ was

21 used for effect size estimation. The Spearman rho coefficient (rho) was

22 applied for correlation analysis. An alpha level below 0.05 was considered 
1 statistically significant. Statistical analyses were performed using SPSS

2 Statistics 22 (IBM, 2011).

\section{3. Results}

4 Seven subjects were excluded from the analysis. Of these, three were

5 excluded due to uncompleted days recorded (2 PD-NC, 1 PDD), and four

6 due to daily wearing time $<80 \%$ (2 PD-NC, 1 PD-MCl, 1 PDD). After

7 exclusion of incomplete recorded days, recordings with a mean of 2

8 complete days (range 1-4) of 48 PD patients (PD-NC, $n=17,35 \%$; PD-MCl,

$9 \mathrm{n}=22,46 \%$; PDD, $\mathrm{n}=9,19 \%)$ were analyzed.

10 The UPDRS III and the GDS scores differed significantly between the

11 cognitive subtypes (PD-NC < PD-MCI < PDD, Table 1). The ordinal logistic

12 regression model was therefore corrected for these confounders. The

13 registered not-wearing time (median $=4$, range $0-280$ minutes) did not

14 differ significantly between the cognitive subgroups.

$15 \quad----$ Please insert Figure 1-3 near here----

$16 \quad 3.1$ Physical behavior outcomes

17 In both PD-NC and PD-MCl groups, the largest proportion of the day was

18 spent lying (PD-NC: 37\%, PD-MCl: 42\%), followed by sitting (PD-NC: 36\%,

19 PD-MCl: 34\%), standing (both 14\%), walking (PD-NC: 5\%, PD-MCl: 4\%),

20 shuffling (PD-NC: 2\%, PD-MCI: 1\%), and not-wearing (<1\%). In the PDD

21 group, the most frequent behavior was sitting (42\%), followed by lying

$22(40 \%)$ (Figure 1). 
1 Descriptively, median values for active physical behavior were relatively

2 low in in the PDD group, but no significant difference in relation to the other

3 cognitive groups was found ( $P>0.05$, Figure 2 and Table 2$)$. Median

4 activity time was $9 \%$ in the PDD group, compared to $21 \%$ in both PD-MCl

5 and PD-NC groups ( $P>0.05$, Table 2$)$. In contrast, median sedentary time

6 was $89 \%$ for PDD, $78 \%$ for PD-MCI, and $75 \%$ for PD-NC $(P>0.05$, Figure

7 2).

8 Walking time was $1.8 \%$ in $\mathrm{PDD}, 3.9 \%$ in $\mathrm{PD}-\mathrm{MCl}(P=0.67, \mathrm{OR}=1.40, \mathrm{Cl}=$

$90.30-6.46)$, and $5.2 \%$ in the PD-NC group $(P=0.44, \mathrm{OR}=2.01, \mathrm{Cl}=0.34-$

10 12.03). Patients with PDD had a median number of 2362 steps, patients

11 with $\mathrm{PD}-\mathrm{MCl} 4742$ steps $(P=0.72, \mathrm{OR}=1.33, \mathrm{Cl}=0.29-6.11)$, and patients

12 with PD-NC 5778 steps $(P=0.48, \mathrm{OR}=1.91, \mathrm{Cl}=0.32-11.42$, Figure 2$)$.

13 The PDD group had a tendency to show low values, however, differences

14 in intensity and energy expenditure parameters were not statistically

15 significant between the groups $(P>0.05$, Table 2$)$. Similarly, time spent in

16 different MET-categories was comparable between the study groups ( $P$ >

$17 \quad 0.05$, Table 2).

18 The groups deviated in the pattern of sedentary behavior (Figure 3). The

19 parameter mean sedentary bout length was significantly longer in PDD

20 (727 s) than in both PD-MCI (515 s, $P=0.02, \mathrm{OR}=0.14, \mathrm{Cl}=0.03-0.69)$ and

21 PD-NC (506 s, $P=0.02, \mathrm{OR}=0.1, \mathrm{Cl}=0.02-0.65$, Figure 3D). Moreover, the

22 PDD group had a reduced number of sedentary bouts (97) compared to the

$23 \mathrm{PD}-\mathrm{MCl}(129, P=0.01, \mathrm{OR}=8.9, \mathrm{Cl}=1.8-45.2)$ and $\mathrm{PD}-\mathrm{NC}$ groups $(134, P=$

$240.01, \mathrm{OR}=10.3, \mathrm{Cl}=1.6-67.3$, Figure $3 \mathrm{C})$. These differences were mainly 
1 caused by fewer, but longer bouts of sitting behavior from the PDD group

$2 \quad(P<0.05$, Figure $3 \mathrm{E}$ and $3 \mathrm{~F})$.

3 3.2 Correlation of sitting parameters with parameters of other

4 behaviors

5 An increase of sitting time correlated significantly with a longer lying time

$6 \quad($ rho $=0.55, P<0.01$, supplementary Figure A) but not with the 'time'

7 parameter of other behaviors (rho $\leq 0.19, P>0.05$ ). A higher sitting

8 intensity correlated with a higher sedentary intensity (rho $=0.84, P<0.01)$

9 and a higher standing intensity (rho $=0.36, P<0.05$ ), but not with the

10 'intensity' parameter of other behaviors (rho $\leq 0.19, P>0.05$ ). An increase

11 in the number of sitting bouts correlated with a higher number of bouts of all

12 other behaviors (rho $\geq 0.65, P<0.01$ ), except for the number of lying bouts

13 (rho $=-0.13, P>0.05)$. An increase in mean sitting bout length was

14 associated with higher 'mean bout length' of both sedentary behavior and

15 shuffling behavior (rho $\geq 0.39, P<0.01$ ), but not with higher 'mean bout

16 length' of other behaviors (rho $\leq 0.14, P>0.05$ ).

17 For the behaviors standing, shuffling, walking, and activity, higher values of

18 the registered 'time', 'intensity', and 'number of bouts' parameters

19 correlated significantly with each other (rho $=0.34$ to rho $=1, P<0.05$ ).

20 Standing mean bout length only correlated with mean walking bout length

21 (rho $=-0.31, P<0.05)$ and mean activity bout length (rho $=0.87, P<0.01$,

22 supplementary Figure A). 
13.3 Correlation of physical behavior outcomes and cognitive

2 tests

3 Lower scores of cognitive tests assessing visuo-construction (e.g. the

4 praxis subtest of the Consortium to establish a registry for Alzheimer's

5 disease (CERAD), as well as the mental rotation and spatial sense

6 subtests of the Leistungsprüfsystem $50+)$ were associated $(P<0.05)$ with

7 the following physical behavior parameters (see supplementary Table A for

8 details): less moderate activity (rho $=0.31$ to 0.47 ), less light activity (rho $=$

$90.30)$, fewer steps (rho $=0.32$ ), lower total movement intensity (rho $=0.35$ ),

10 lower number of activity bouts (rho $=0.31$ ), longer mean activity bout length

11 (rho $=-0.30)$, more sedentary activity (rho $=-0.36)$, and lower number of

12 sedentary bouts (rho $=0.32$ ). More impaired attention performance,

13 represented by at least one of the Stroop-test sub scores, word naming or

14 color naming, correlated significantly with longer mean activity bout length

15 (rho $=-0.34)$, less moderate activity (rho $=0.34)$, lower total movement

16 intensity (rho $=0.30$ to 0.34 ), and more sedentary activity (rho $=-0.33$,

17 supplementary Table A). Decreased performance on the Trail making test

$18 \mathrm{~A} / \mathrm{B}$, assessing executive function, was associated with less moderate

19 activity (rho $=0.31$ ) and a lower number of activity bouts (rho $=0.30$ ).

20 Reduced phonematic verbal fluency correlated with shorter sedentary time

21 (rho $=0.30)$. Worse memory performance (e.g. word-list recall) was

22 associated with higher activity intensity (rho $=-0.31$ ) and a higher number

23 of steps (rho $=-0.30)$. 


\section{4. Discussion}

2 In this pilot study, PDD patients showed a tendency for low median values

3 of active and intensive physical behavior parameters and high median

$4 \quad$ values for sedentary parameters. These differences were not significant in

5 the statistical model applied to adjust for depressive symptoms and motor

6 impairment. However, statistically significant differences with relatively high

7 effect sizes were observed in the pattern of sedentary physical behavior:

8 PDD patients had fewer, but longer sedentary bouts than both participants

9 with PD-NC and PD-MCI.

10 The dominant role of sedentary behavior is further supported by two

11 interesting observations of this study. First, unlike the other cognitive

12 subgroups, the most frequent behavior of the PDD group was sitting.

13 Second, the results of the correlation analysis showed that most of the

14 sitting behavior parameters were relatively poorly associated with the

15 parameters of other behaviors. These results could indicate a special role

16 of sedentary, especially sitting, parameters among all physical behavior

17 parameters assessed in our study.

18 To the best of our knowledge, this is the first study to explore the physical

19 behavior profile of cognitive subtypes in PD. Dontje and colleagues [14]

20 reported that 586 PD patients showed a relevant but weak correlation

21 between MMSE score and energy expenditure using actigraphy. Though

22 our study did not reproduce this finding with statistical significance,

23 descriptive values support their findings. The lack of statistical power could 
1 be due to the relatively small PDD cohort or its relatively large

2 heterogeneity.

3 Our findings do however support the reports of Chastin and colleagues

4 [13], who showed that late stage PD patients had longer sedentary bout

5 lengths. Moreover, Chen and colleagues [5] compared ADL scores,

6 assessed by the Tokyo Metropolitan Institute of Gerontology Index of

7 Competence, with accelerometer data of 1634 older adults. They found a

8 relevant association between ADL disability and greater volume of

9 sedentary behavior, as well as a lower number of sedentary bouts. Taking

10 our findings and the results of the aforementioned studies into account, the

11 hypothesis that alterations in the sedentary physical behavior pattern,

12 specifically fewer but longer sedentary bouts, could be associated with ADL

13 impairment in PD, seems possible.

14 In accordance with previous study results [29-34], our data confirmed that

15 less active physical behavior correlated with lower scores on tests

16 assessing visuo-construction, attention and executive functions, but not

17 verbal fluency, memory and language performance. This indicates that the

18 physical behavior profile can, at least partly, reflect cognitive worsening

19 associated with the domains mentioned above. Linking memory function

20 with physical behavior is controversial, as only one study so far has

21 identified a significant correlation [31]. Therefore, more studies are needed

22 to investigate the relation between cognition and physical behavior in older

23 adults and in dementia. 
1 Limitations of this study were: first, sample size and heterogeneity of the

2 PDD group limited the generalization of our results. Second, no statistical

3 correction for multiple testing was applied. To reduce the influence of these

4 limitations, we used non parametric testing.

5 As can be seen in the scatter dot plots, there may be subgroups that

6 specifically drive group differences. Further analysis of these outliers

7 revealed a very heterogenic picture of both participants with only a few

8 extreme values ( $\leq 4$ parameters: $56 \%$ of participants), and participants with

9 several extreme values ( $\geq 4$ parameters: $23 \%$ of participants). The latter

10 group could be further categorized into participants with very active

11 physical behavior (10\%), participants with very sedentary behavior (8\%),

12 and participants with very few bouts (4\%). Therefore, the exclusion of

13 outliers with an arbitrary cut-off value bears a high risk of excluding patients

14 with heavier disease burden. Moreover, several other studies have

15 reported a considerable heterogeneity in advanced disease stages of both

16 PD [14] and dementia [35-37].

17 Third, a complete separation between motor impact and cognitive/ADL

18 dysfunction impact on physical behavior is currently not possible. However,

19 we did reduce possible confounding effects by statistically correcting for the

20 UPDRS III motor score.

21 It should also be noted that because of the abilities of current sensor

22 technology and data analysis techniques, the presented output parameters

23 cannot serve as absolute descriptions of daily physical behavior, but rather

24 enable the comparison of group performances. 
1 Strengths of our study are the inclusion and successful assessment of

2 patients with later disease stages, as well as the use of modern wearable

3 technology, which allowed us to evaluate a comprehensive and detailed

4 range of physical behavior outcomes.

5 Results of this pilot study indicate that there are associations between the

6 sedentary physical behavior pattern and ADL-impairment in PDD. This

7 helps in identifying promising parameters that have the potential to improve

8 the differentiation of PDD from both PD-NC and PD-MCI. To consolidate

9 our findings, further studies with larger study samples, especially the PDD

10 group, are necessary. Our results support the potential of objective physical

11 behavior assessment in further understanding, screening, diagnosing,

12 predicting, and monitoring cognitive impairment in PD.

14 Acknowledgments. We thank all participants of our study. For this study,

15 part of the data was generated within the DEMPARK/LANDSCAPE study.

16 The DEMPARK study is being funded by an unrestricted grant from

17 Novartis and a grant from the International Parkinson Fonds (Deutschland)

$18 \mathrm{gGmbH}$ (IPD). The LANDSCAPE study is part of the Competence Network

19 Degenerative Dementias (KNDD) which was funded by the German

20 Federal Ministry of Education and Research (project number 01GI1008C).

21 We would also like to thank Lynn Rochester and Sara Becker for the

22 helpful comments for the preparation of our manuscript. 
1 Declaration of Conflicting Interests. Rob C. van Lummel is a PhD

2 student at the Faculty of Human Movement Sciences (Vrije Universiteit

3 Amsterdam) and the owner of McRoberts. Jos Prinzen is an employee of

4 McRoberts. This company is the manufacturer of the DynaPort.

5 Funding. The accelerometry assessment applied in this study received no

6 special funding 


\section{References}

[1] Aarsland D, Zaccai J, Brayne C, A systematic review of prevalence studies of dementia in Parkinson's disease. MovDisord 2005; 20: 1255-1263.

[2] Hely MA, Reid WGJ, Adena MA, Halliday GM, Morris JGL, The Sydney multicenter study of Parkinson's disease: the inevitability of dementia at 20 years. MovDisord 2008; 23: 837-844.

[3] Emre M, Aarsland D, Albanese A, Byrne EJ, Deuschl G, De Deyn PP, et al., Rivastigmine for dementia associated with Parkinson's disease. NEnglJMed 2004; 351: $2509-2518$.

[4] Maetzler W, Rochester L, Body-worn sensors-the brave new world of clinical measurement? MovDisord 2015;30: 1203-1205.

[5] Chen T, Narazaki K, Haeuchi Y, Chen S, Honda T, Kumagai S, Associations of Sedentary Time and Breaks in Sedentary Time With Disability in Instrumental Activities of Daily Living in Community-Dwelling Older Adults. JPhysActHealth 2016; 13: 303-309. DOI:10.1123/jpah.2015-0090.

[6] Dunlop DD, Song J, Arnston EK, Semanik PA, Lee J, Chang RW, et al., Sedentary time in US older adults associated with disability in activities of daily living independent of physical activity. JPhysActHealth 2015; 12: 93-101.

[7] Emre M, Aarsland D, Brown R, Burn DJ, Duyckaerts C, Mizuno Y, et al., Clinical diagnostic criteria for dementia associated with Parkinson's disease. MovDisord 2007; 22: 1689-707. 
[8] Litvan I, Goldman JG, Tröster AI, Schmand BA, Weintraub D, Petersen RC, et al., Diagnostic criteria for mild cognitive impairment in Parkinson's disease: Movement Disorder Society Task Force guidelines. MovDisord 2012; 27: 349-356.

[9] Ahlskog JE, Geda YE, Graff-Radford NR, Petersen RC, Physical exercise as a preventive or disease-modifying treatment of dementia and brain aging. MayoClin.Proc 2011; 86: 876-884.

[10] Keus SJH, Bloem BR, Hendriks EJM, Bredero-Cohen AB, Munneke M, Practice Recommendations Development Group, Evidence-based analysis of physical therapy in Parkinson's disease with recommendations for practice and research. MovDisord 2007; 22: 451-60.

[11] Kwakkel G, de Goede CJT, van Wegen EEH, Impact of physical therapy for Parkinson's disease: a critical review of the literature. ParkinsonismRelatDisord 2007; 13 Suppl 3: 478-487.

[12] Sofi F, Valecchi D, Bacci D, Abbate R, Gensini GF, Casini A, et al., Physical activity and risk of cognitive decline: a meta-analysis of prospective studies. JInternMed 2011; 269: 107-117.

[13] Chastin SFM, Baker K, Jones D, Burn D, Granat MH, Rochester L, The pattern of habitual sedentary behavior is different in advanced Parkinson's disease. MovementDisorders 2010; 25: 2114-2120.

[14] Dontje ML, de Greef MH, Speelman AD, van Nimwegen M, Krijnen WP, Stolk RP, et al., Quantifying daily physical activity and determinants in sedentary patients with Parkinson's disease. ParkinsonismRelat.Disord 2013; 19: 878-882. 
[15] Balzer-Geldsetzer M, da Costa AFSB, Kronenbürger M, Schulz JB, Röske S, Spottke A, et al., Parkinson's disease and dementia: a longitudinal study (DEMPARK). Neuroepidemiology 2011; 37: 168-176.

[16] Folstein MF, Folstein SE, McHugh PR, "Mini-mental state". A practical method for grading the cognitive state of patients for the clinician. JPsychiatrRes 1975; 12: 189 198.

[17] Fahn S, Elton R: Unified rating scale for Parkinson's disease; in Fahn S, Marsden CD, Calne DB, Goldstein M (eds): Recent developments Parkinson's disease. Florham Park, Macmillan, 1987, pp 153-163.

[18] Hoehn MM, Yahr MD, Parkinsonism: onset, progression and mortality. Neurology 1967; 17: 427-442.

[19] Tomlinson CL, Stowe R, Patel S, Rick C, Gray R, Clarke CE, Systematic review of levodopa dose equivalency reporting in Parkinson's disease. MovDisord 2010; 25: 2649-2653.

[20] Kalbe E, Calabrese P, Kohn N, Hilker R, Riedel O, Wittchen H-U, et al., Screening for cognitive deficits in Parkinson's disease with the Parkinson neuropsychometric dementia assessment (PANDA) instrument. ParkinsonismRelatDisord 2008; 14: 93101.

[21] Yesavage JA, Sheikh JI, 9/Geriatric Depression Scale (GDS). ClinicalGerontologist 1986; 5: 165-173. 
[22] Van Hees VT, Slootmaker SM, De Groot G, Van Mechelen W, Van Lummel RC, Reproducibility of a triaxial seismic accelerometer (DynaPort). MedSciSportsExerc 2009; 41: 810-817.

[23] Dijkstra B, Kamsma YP, Zijlstra W, Detection of gait and postures using a miniaturized triaxial accelerometer-based system: accuracy in patients with mild to moderate Parkinson's disease. ArchPhysMedRehabil 2010; 91: 1272-1277.

[24] Dijkstra B, Zijlstra W, Scherder E, Kamsma Y, Detection of walking periods and number of steps in older adults and patients with Parkinson's disease: accuracy of a pedometer and an accelerometry-based method. AgeAgeing 2008; 37: 436-441.

[25] Lord S, Godfrey A, Galna B, Mhiripiri D, Burn D, Rochester L, Ambulatory activity in incident Parkinson's: more than meets the eye? J.Neurol 2013; 260: 2964-2972.

[26] van Hees VT, van Lummel RC, Westerterp KR, Estimating activity-related energy expenditure under sedentary conditions using a tri-axial seismic accelerometer. Obesity(SilverSpring). 2009; 17: 1287-1292.[27] Catellier DJ, Hannan PJ, Murray DM, et al., Imputation of missing data when measuring physical activity by accelerometry. Med Sci Sports Exerc 2005;37(11 Suppl):555-562.

[27] Catellier DJ, Hannan PJ, Murray DM, et al., Imputation of missing data when measuring physical activity by accelerometry. Med Sci Sports Exerc 2005;37(11 Suppl):555-562.

[28] Harrell Jr FE: Regression Models for Continuous Y and Case Study in Ordinal Regression. Regression Modeling Strategies. Cham, Springer International Publishing, 2015, pp 359-387. 
[29] Barnes DE, Blackwell T, Stone KL, Goldman SE, Hillier T, Yaffe K, et al., Cognition in older women: the importance of daytime movement. JAmGeriatrSoc 2008; 56 : $1658-1664$.

[30] Brown BM, Peiffer JJ, Sohrabi HR, Mondal A, Gupta VB, Rainey-Smith SR, et al., Intense physical activity is associated with cognitive performance in the elderly. TransIPsychiatry 2012; 2: e191.

[31] AS Buchman, RS Wilson, Bennett DA, Total daily activity is associated with cognition in older persons. AmJGeriatrPsychiatry 2008; 16: 697-701.

[32] Doi T, Makizako H, Shimada H, Tsutsumimoto K, Hotta R, Nakakubo S, et al., Objectively measured physical activity, brain atrophy, and white matter lesions in older adults with mild cognitive impairment. ExpGerontol 2015; 62: 1-6.

[33] Makizako H, Liu-Ambrose T, Shimada H, DOI T, Park H, Tsutsumimoto K, et al., Moderate-Intensity Physical Activity, Hippocampal Volume, and Memory in Older Adults With Mild Cognitive Impairment. JGerontolABiolSciMedSci 2014.

[34] Wilbur J, Marquez DX, Fogg L, Wilson RS, Staffileno BA, Hoyem RL, et al., The relationship between physical activity and cognition in older Latinos. JGerontolBPsycholSciSocSci 2012; 67: 525-534.

[35] Fleiner T, Haussermann P, Mellone S, Zijlstra W: Sensor-based assessment of mobility-related behavior in dementia: feasibility and relevance in a hospital context. International Psychogeriatrics 2016;28(10):1687-1694. doi:10.1017/s1041610216001034. 
[36] Harper DG, Stopa EG, McKee AC, et al. Differential circadian rhythm disturbances in men with Alzheimer disease and frontotemporal degeneration. Arch Gen Psychiatry 2001;58(4):353-360.

[37] Nagels G, Engelborghs S, Vloeberghs E, Van Dam D, Pickut BA, De Deyn PP. Actigraphic measurement of agitated behaviour in dementia. Int J Geriatr Psychiatry 2006;21(4):388-393. doi:10.1002/gps.1483. 


\section{Legend}

Figure 1 Overview of total time spent in different behaviors for the three study groups; PDNC, Parkinson's disease with no cognitive impairment; PD-MCl, Parkinson's disease with mild cognitive impairment; PDD, Parkinson's disease dementia. Values were calculated using the ratio of each median with all summed medians of the study group.

Figure 2 Comparisons of physical behavior parameters between the three study groups; PD-NC, Parkinson's disease with no cognitive impairment; PD-MCI, Parkinson's disease with mild cognitive impairment; PDD, Parkinson's disease dementia. Data is presented with median and interquartile range.

Figure 3 Comparisons of the physical behavior pattern between the three study groups: PDNC, Parkinson's disease with no cognitive impairment; PD-MCI, Parkinson's disease with mild cognitive impairment; PDD, Parkinson's disease dementia. Data is presented with median and interquartile range. Statistically significant differences adjusted for depression (GDS) and motor impairment (UPDRS III) scores are presented with brackets, odds ratio $(\mathrm{OR})$ with $95 \%$ confidence interval $(\mathrm{Cl})$ and $\mathrm{p}$-values $(\mathrm{P})$. 
Table 1 Characterization of the study sample.

\begin{tabular}{lllll}
\hline Variable & \multicolumn{3}{c}{ Median (Minimum/Maximum) } & p-value \\
& PD-NC (n=17) & PD-MCI (n=22) & PDD (n=9) & \\
\hline Age & $71(44 / 80)$ & $68(57 / 78)$ & $72(67 / 75)$ & 0.18 \\
Male gender, $n(\%)$ & $10(59 \%)$ & $17(77 \%)$ & $9(100 \%)$ & 0.09 \\
Age of onset & $64(43 / 72)$ & $61(43 / 71)$ & $65(55 / 69)$ & 0.43 \\
Disease duration (years) & $6(1 / 13)$ & $6(1 / 20)$ & $6(5 / 18)$ & 0.11 \\
Hoehn \& Yahr Stage, n (\%) & & & & \\
1 & $6(35 \%)$ & $3(14 \%)$ & - & \\
2 & $10(59 \%)$ & $13(59 \%)$ & $3(33 \%)$ & $\mathbf{0 . 0 3}$ \\
3 & $1(6 \%)$ & $4(18 \%)$ & $3(33 \%)$ & \\
4 & - & $2(9 \%)$ & $2(22 \%)$ & \\
5 & - & - & $1(11 \%)$ & \\
UPDRS-III score & $20(11 / 58)$ & $24(10 / 62)$ & $36(14 / 56)$ & $\mathbf{0 . 0 1}$ \\
LEDD & $620(160 / 2420)$ & $763(210 / 2378)$ & $496(100 / 1139)$ & 0.16 \\
Geriatric Depression Scale (GDS) & $2(0 / 6)$ & $5(0 / 10)$ & $8(3 / 15)$ & $\mathbf{0 . 0 0 1}$ \\
\hline
\end{tabular}

LEDD, Levodopa equivalence daily dose; $n$, number; PDD, Parkinson's disease dementia; PD-MCl,

Parkinson's disease with mild cognitive impairment; PD-NC, Parkinson's disease with no cognitive impairment; UPDRS-III, Unified Parkinson's disease Rating Scale part III. 
Table 2 Group comparisons adjusted for depression (GDS) and motor impairment (UPDRS-III) scores.

\begin{tabular}{|c|c|c|c|c|c|c|c|c|c|}
\hline & \multicolumn{3}{|c|}{ Median (Minimum/Maximum) } & \multicolumn{3}{|c|}{ PD-NC vs. PDD } & \multicolumn{3}{|c|}{ PD-MCI vs. PDD } \\
\hline & PD-ND & PD-MCI & PDD & $\mathrm{p}$-value & OR & $\mathrm{Cl}(95 \%)$ & $p$-value & OR & $\mathrm{Cl}(95 \%)$ \\
\hline$\overline{\text { Activity time [\%] }}$ & $0.21(0.03 / 0.41)$ & $0.21(0.08 / 0.39)$ & $0.09(0.01 / 0.26)$ & 0.22 & 3.05 & $0.50 / 18.53$ & 0.28 & 2.35 & $0.50 / 10.99$ \\
\hline \multicolumn{10}{|c|}{ Time spent in activity (standing, shuffling, walking) } \\
\hline Activity intensity [g] & $0.08(0.03 / 0.13)$ & $0.07(0.03 / 0.11)$ & $0.07(0.03 / 0.13)$ & 0.89 & 1.13 & $0.19 / 6.72$ & 0.56 & 0.63 & $0.14 / 2.93$ \\
\hline \multicolumn{10}{|l|}{ Mean intensity of activity } \\
\hline PAR of activity & $2.29(1.35 / 3.13)$ & $2.16(1.43 / 2.87)$ & $2.20(1.39 / 3.08)$ & 0.79 & 1.27 & $0.21 / 7.54$ & 0.64 & 0.70 & $0.15 / 3.21$ \\
\hline \multicolumn{10}{|l|}{ Relative EE to BMR of activity } \\
\hline Number of activity bouts & $1555(58 / 6385)$ & $1470(364 / 5011)$ & $859(49 / 2329)$ & 0.32 & 2.48 & $0.41 / 14.90$ & 0.37 & 2.01 & $0.43 / 9.38$ \\
\hline \multicolumn{10}{|l|}{ Number of activity periods (=bouts) } \\
\hline Mean activity bout length [s] & $8.50(0 / 41.24)$ & $11.03(6.06 / 23.91)$ & $12.02(7.22 / 19.84)$ & 0.48 & 0.53 & $0.09 / 3.16$ & 0.89 & 1.11 & $0.24 / 5.13$ \\
\hline \multicolumn{10}{|l|}{ Mean boutlength for performed activity bouts } \\
\hline Sedentary time [\%] & $0.75(0.51 / 0.97)$ & $0.78(0.61 / 0.92)$ & $0.89(0.74 / 0.97)$ & 0.10 & 0.21 & $0.03 / 1.33$ & 0.14 & 0.31 & $0.07 / 1.48$ \\
\hline \multicolumn{10}{|c|}{ Time spent sedentary behavior (lying and sitting) } \\
\hline Sedentary intensity [g] & $0.01(0.01 / 0.04)$ & $0.01(0.01 / 0.04)$ & $0.01(0 / 0.04)$ & 0.60 & 1.60 & $0.27 / 9.53$ & 0.60 & 1.51 & $0.33 / 6.96$ \\
\hline \multicolumn{10}{|l|}{ Mean Intensity of sedentary behavior } \\
\hline PAR of sedentary & $1.18(1.14 / 1.66)$ & $1.21(1.12 / 1.58)$ & $1.17(1.13 / 1.64)$ & 0.77 & 1.30 & $0.22 / 7.74$ & 0.47 & 1.77 & $0.38 / 8.20$ \\
\hline \multicolumn{10}{|l|}{ Relative EE to BMR of sedentary behavior } \\
\hline Number of sedentary bouts & $134(63 / 219)$ & $129(43 / 711)$ & $97(22 / 159)$ & 0.01 & 10.30 & $1.58 / 67.25$ & 0.01 & 8.90 & $1.75 / 45.23$ \\
\hline \multicolumn{10}{|l|}{ Number of sedentary periods (=bouts) } \\
\hline Mean sedentary bout length [s] & $506(208 / 1344)$ & $515(83 / 1441)$ & $727(402 / 3869)$ & 0.02 & 0.10 & $0.02 / 0.65$ & 0.02 & 0.14 & $0.03 / 0.69$ \\
\hline \multicolumn{10}{|l|}{ Mean boutlength for performed sedentary bouts } \\
\hline Steps & $5778(43 / 14164)$ & $4742(167 / 10181)$ & $2362(15 / 13346)$ & 0.48 & 1.91 & $0.32 / 11.42$ & 0.72 & 1.33 & $0.29 / 6.11$ \\
\hline \multicolumn{10}{|l|}{ Number of steps performed per day } \\
\hline Total movement intensity [g] & $0.03(0.02 / 0.06)$ & $0.03(0.01 / 0.06)$ & $0.03(0.006 / 0.04)$ & 0.76 & 1.32 & $0.22 / 7.82$ & 0.90 & 0.90 & $0.20 / 4.16$ \\
\hline Mean Intensity of overall physical behavior & & & & & & & & & \\
\hline
\end{tabular}




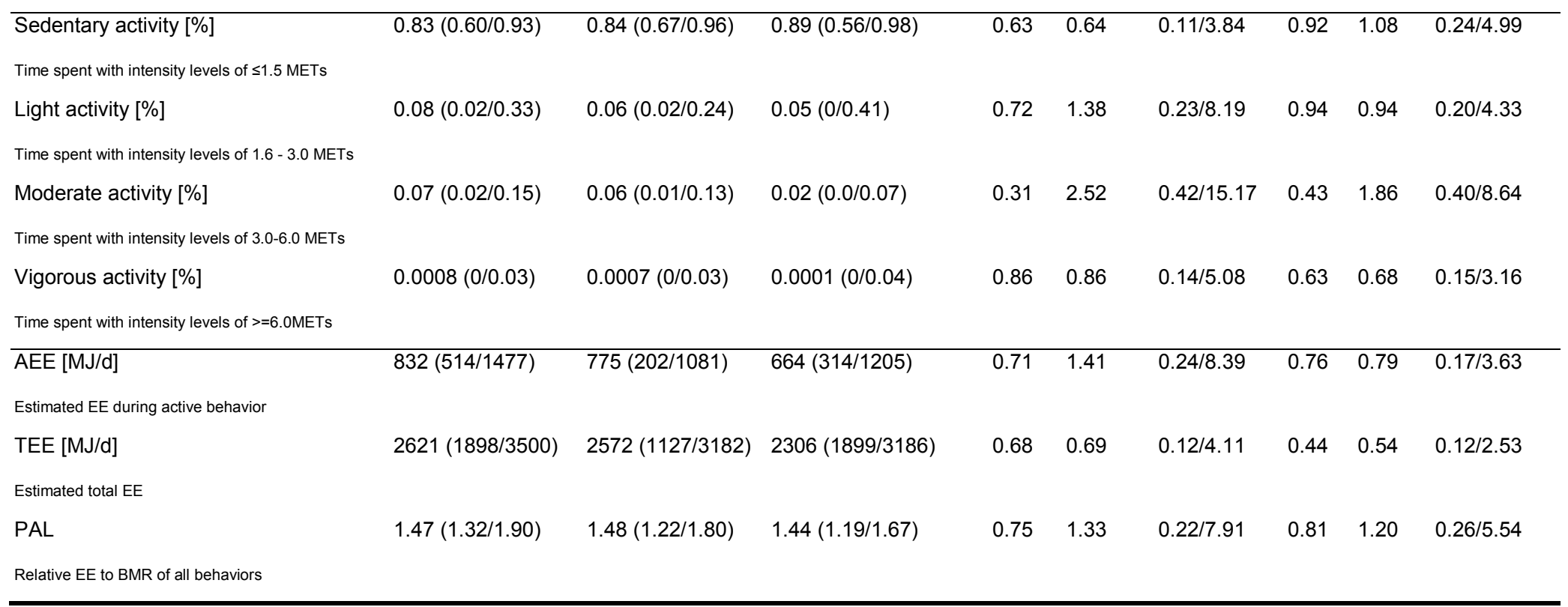

AEE, activity related energy expenditure; BMR, Basal Metabolic Rate; Cl, Confidence Interval; EE, Energy Expenditure; GDS, Geriatric Depression Scale; MET,

Mean equivalent of task; OR, Odds Ratio; PAL, physical activity level; PAR, physical activity ratio; PDD, Parkinson's disease dementia; PD-MCI, Parkinson's

disease with mild cognitive impairment; PD-NC, Parkinson's disease with no cognitive impairment; TEE, Total energy expenditure; UPDRS-III, Unified Parkinson

Disease Rating Scale part III; P values $<0.05$ are shown in bold. 







\section{Active physical behavior}

A.

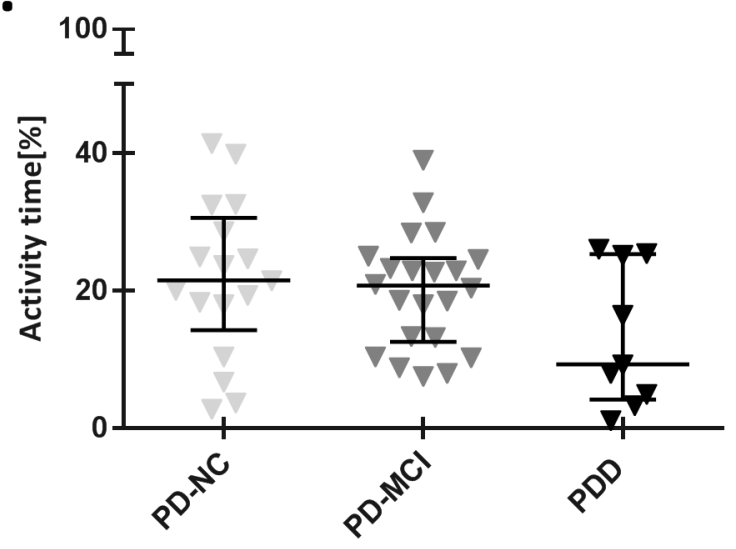

C.

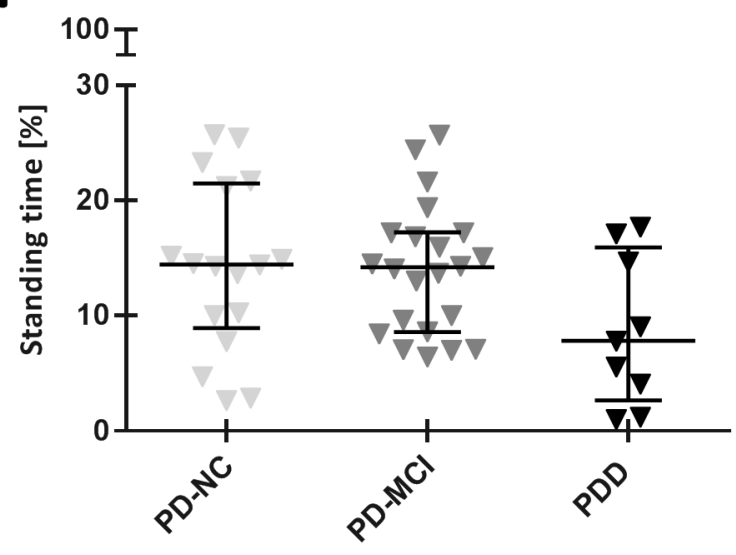

E.

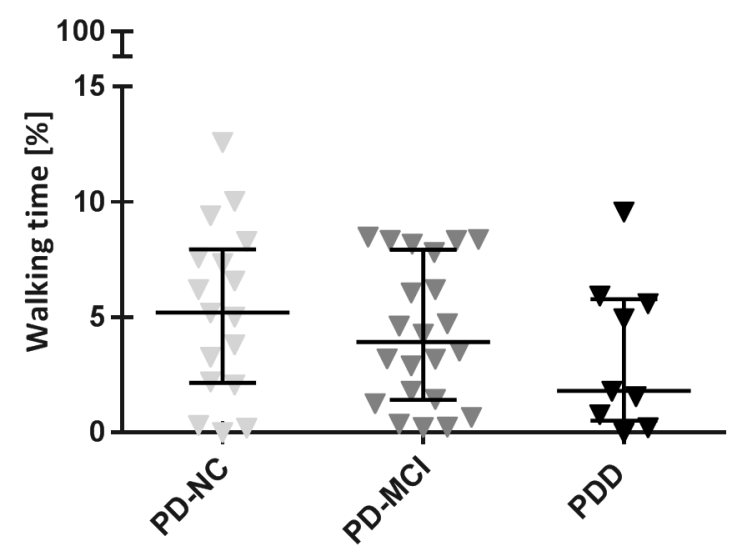

G.

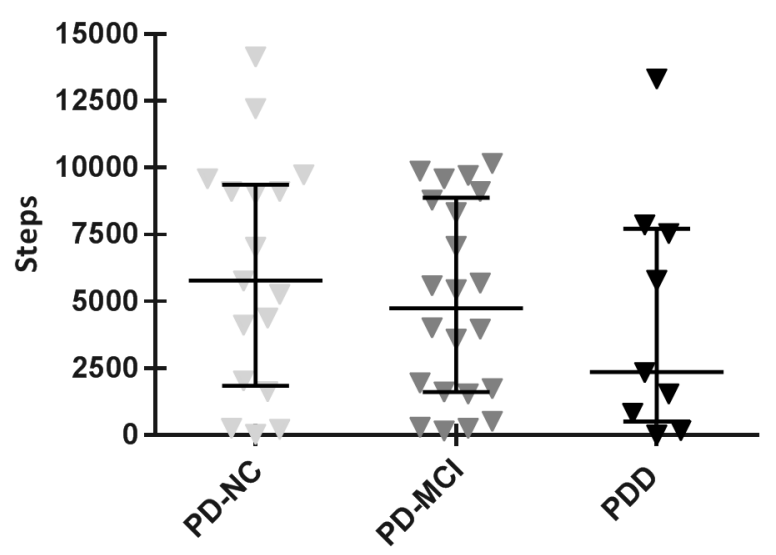

B.

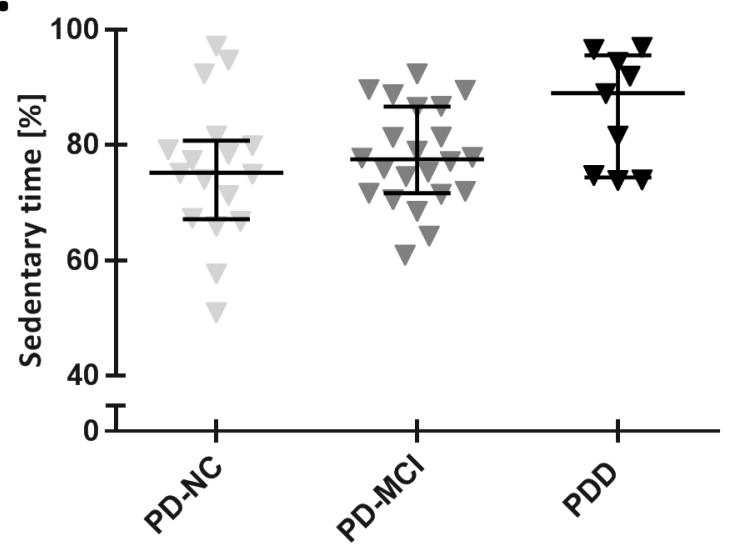

D.

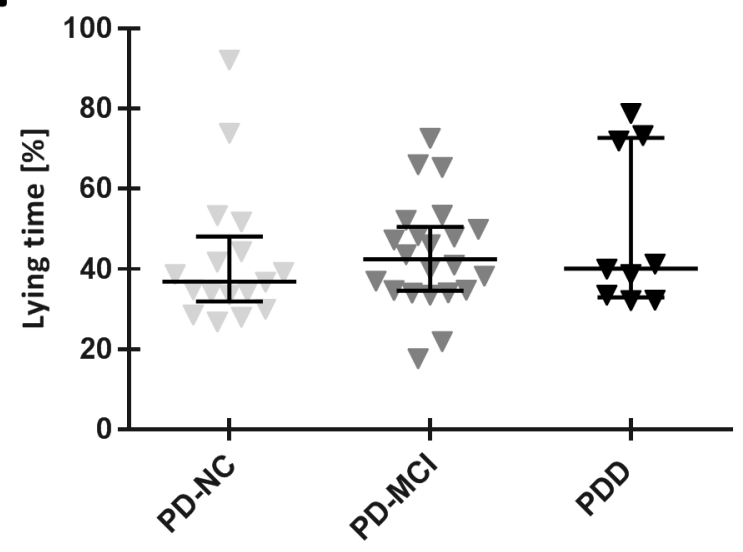

F.

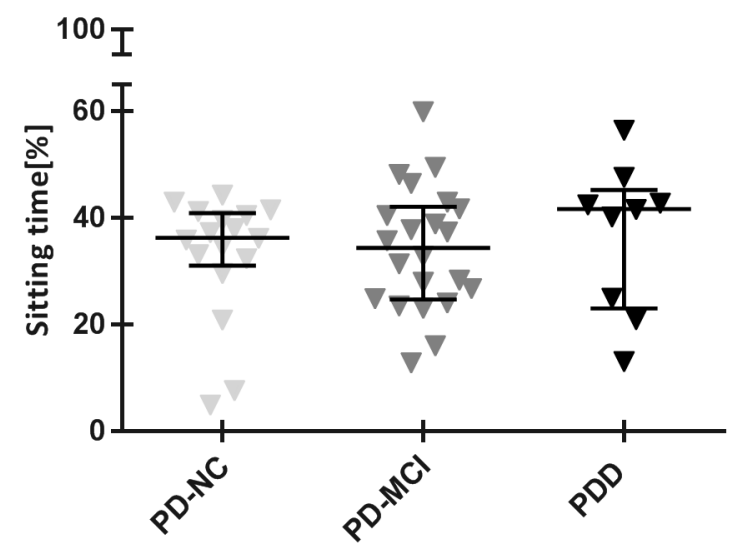


A.

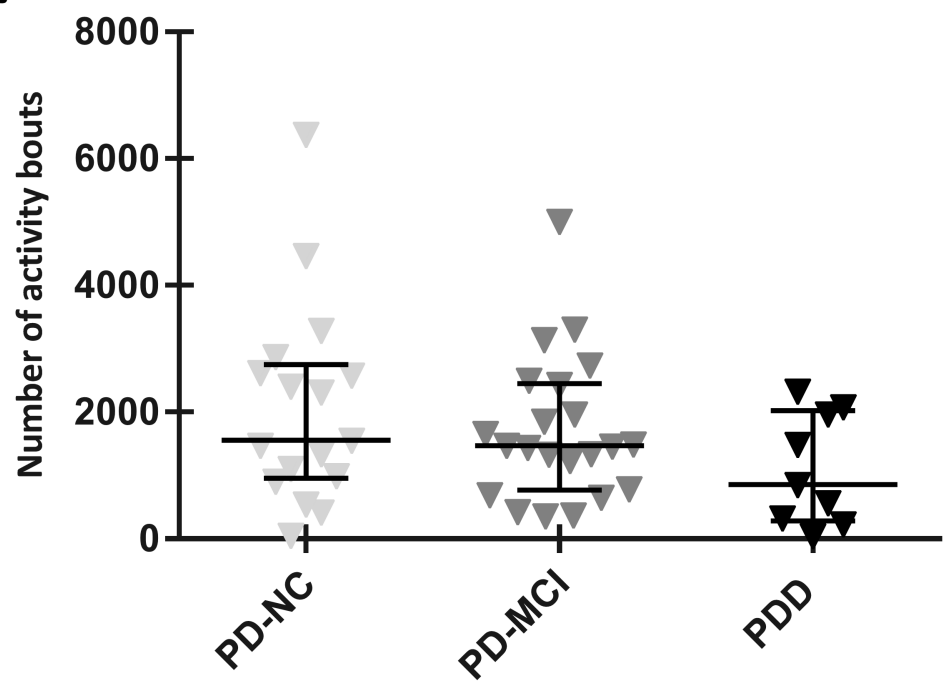

C.

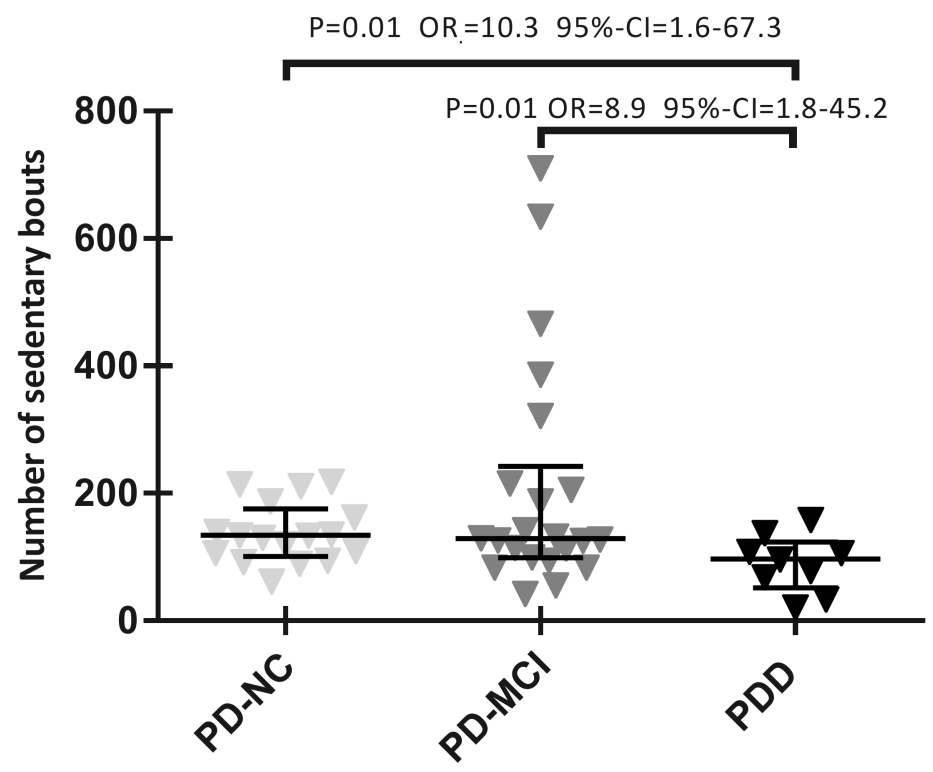

E.

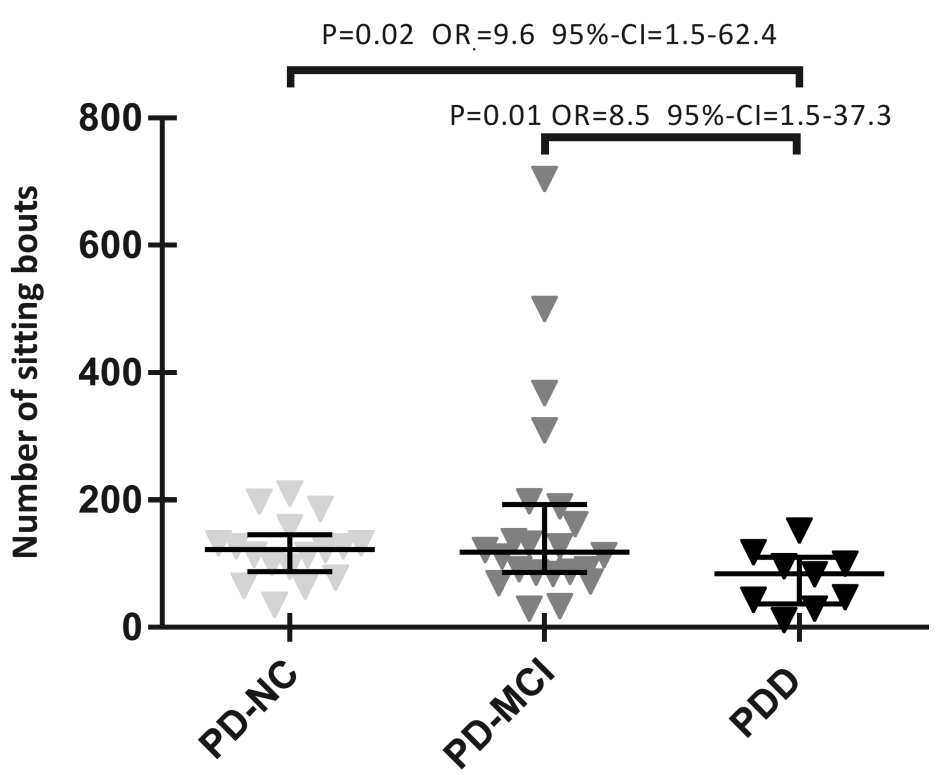

B.



D.

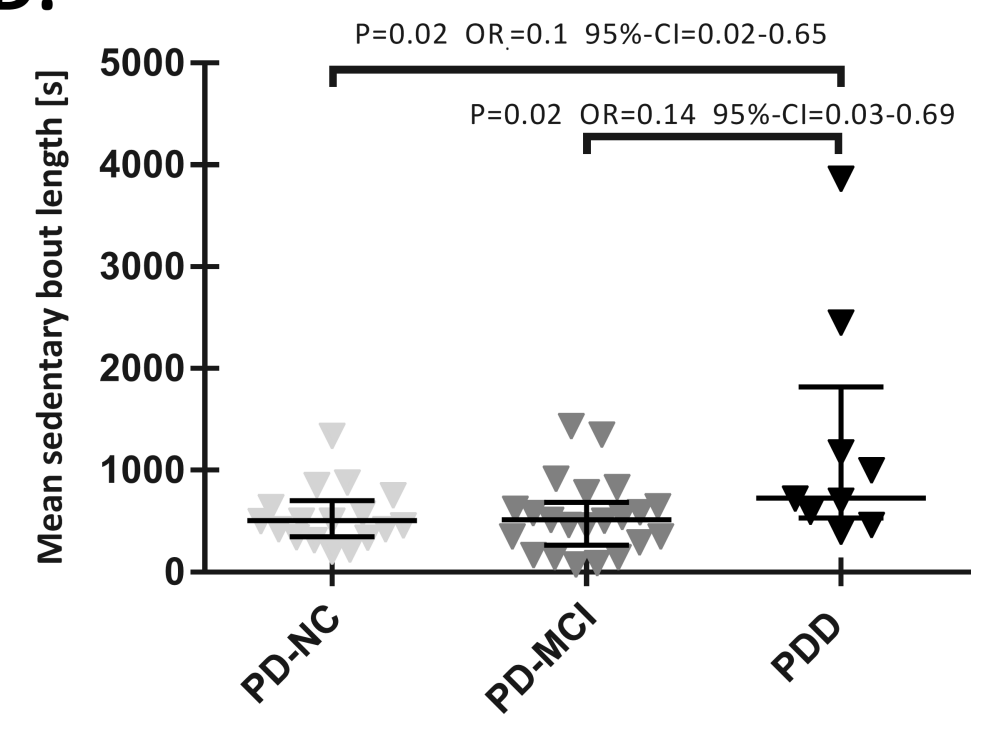

F.

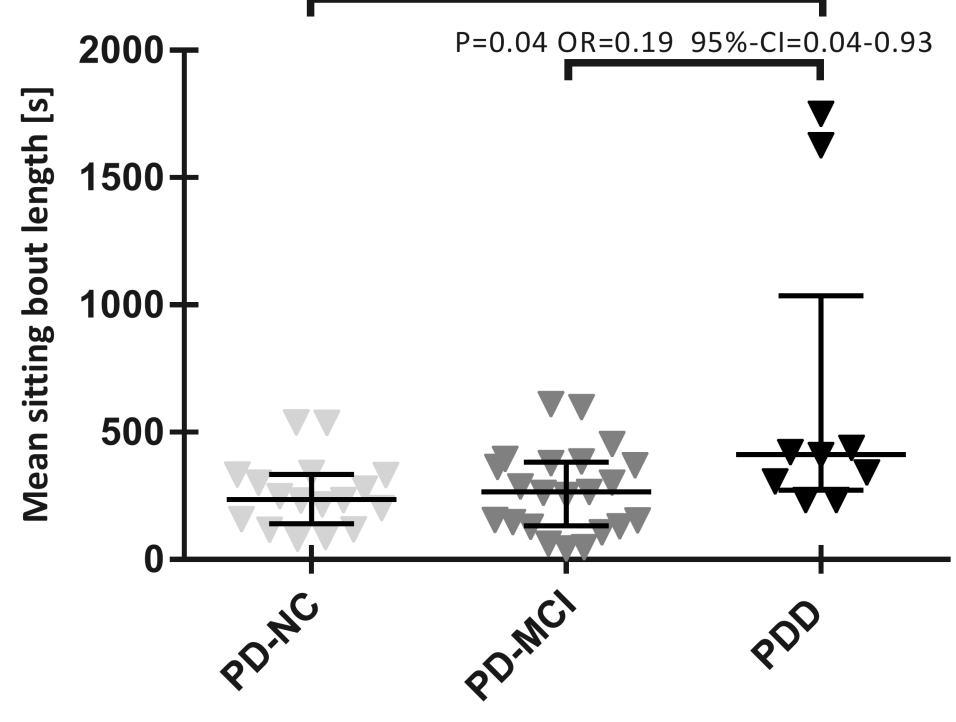


Table A Correlations between selected neuropsychological tests and physical behavior parameters

\begin{tabular}{|c|c|c|c|c|c|c|c|c|c|c|c|c|c|c|c|}
\hline Test & Function & $\begin{array}{l}\text { Activity } \\
\text { time }\end{array}$ & $\begin{array}{l}\text { Activity } \\
\text { intensity }\end{array}$ & $\begin{array}{l}\text { Number of } \\
\text { activity } \\
\text { bouts }\end{array}$ & $\begin{array}{l}\text { Mean } \\
\text { activity } \\
\text { bout } \\
\text { length }\end{array}$ & $\begin{array}{l}\text { Sedentary } \\
\text { time }\end{array}$ & $\begin{array}{l}\text { Sedentary } \\
\text { intensity }\end{array}$ & $\begin{array}{l}\text { Number of } \\
\text { sedentary } \\
\text { bouts }\end{array}$ & $\begin{array}{l}\text { Mean } \\
\text { sedentary } \\
\text { bout } \\
\text { length }\end{array}$ & Steps & $\begin{array}{l}\text { Total } \\
\text { movement } \\
\text { intensity }\end{array}$ & $\begin{array}{l}\text { Sedentary } \\
\text { activity }\end{array}$ & $\begin{array}{l}\text { Light } \\
\text { activity }\end{array}$ & $\begin{array}{l}\text { Moderate } \\
\text { activity }\end{array}$ & $\begin{array}{l}\text { Vigorous } \\
\text { activity }\end{array}$ \\
\hline MMSE & Global cognition & -.07 & .13 & .09 & -.17 & .09 & .09 & .04 & -.02 & .08 & .21 & -.20 & .11 & .19 & .15 \\
\hline WMS-R: Digit Span forward" & Working memory & .16 & .17 & .16 & -.11 & -.10 & -.09 & .20 & -.19 & .26 & -.05 & .14 & -.20 & .18 & .20 \\
\hline WMS-R: Digit Span backward\# & Working memory & -.06 & .06 & .01 & -.10 & .07 & -.01 & .07 & -.05 & .05 & -.11 & .11 & -.07 & -.06 & -.02 \\
\hline CERAD: Word-list recall ${ }^{\#}$ & Verbal memory & -.15 & $-.31^{*}$ & -.22 & .14 & .07 & .15 & -.18 & .14 & $-.30^{*}$ & -.05 & -.07 & .13 & -.17 & -.26 \\
\hline CERAD: Semantic fluency ${ }^{\#}$ & Word generation & .13 & .01 & .16 & -.15 & -.09 & .20 & .22 & -.22 & .05 & .22 & -.25 & .22 & .24 & -.05 \\
\hline CERAD: Phonematic fluency ${ }^{\#}$ & Word generation & -.26 & -.20 & -.20 & -.01 & $.30^{*}$ & .15 & -.25 & .26 & -.24 & .01 & -.12 & .20 & -.09 & -.14 \\
\hline Trail Making Test: Part $\mathrm{A}^{\#}$ & Psychomotor speed & -.22 & .05 & -.10 & .01 & .27 & .15 & -.20 & .23 & -.11 & .12 & -.18 & .25 & -.08 & -.07 \\
\hline Trail Making Test: Part $\mathrm{B}^{\#}$ & Psychomotor speed/Set shifting & .10 & .23 & .18 & -.19 & .00 & .02 & -.08 & .08 & .16 & .23 & -.14 & .08 & .29 & .09 \\
\hline Trail Making Test: $A / \mathrm{B}^{\#}$ & Set shifting & .29 & .23 & $.30^{*}$ & -.28 & -.19 & -.14 & -.02 & -.03 & .26 & .09 & .07 & -.16 & $.31^{*}$ & .08 \\
\hline CERAD: Praxis ${ }^{\#}$ & Visuo-construction & .20 & .27 & .23 & -.15 & -.13 & $-.30^{*}$ & $.32^{*}$ & -.29 & .25 & -.12 & .22 & -.27 & .20 & .13 \\
\hline LPS 50+ 7: Mental Rotation" & Visuo-construction & .28 & .29 & $.31^{*}$ & -.19 & -.22 & -.08 & .09 & -.13 & $.32^{*}$ & .26 & -.17 & .02 & $.47^{* *}$ & .29 \\
\hline LPS 50+ 9: Spatial Sense ${ }^{\#}$ & Visuo-construction & .13 & .18 & .21 & $-.30^{*}$ & -.02 & .23 & .11 & -.10 & .20 & $.35^{*}$ & $-.36^{*}$ & $.30^{*}$ & $.31^{*}$ & .14 \\
\hline Stroop: Word naming & Directed attention & .11 & .24 & .24 & $-.34^{*}$ & -.03 & .12 & .11 & -.13 & .16 & $.30^{*}$ & -.24 & .17 & $.34^{*}$ & .06 \\
\hline Stroop: Color naming & Directed attention & .18 & .24 & .28 & $-.34^{*}$ & -.12 & .21 & .19 & -.23 & .16 & $.34^{*}$ & $-.33^{*}$ & .26 & $.34^{*}$ & .07 \\
\hline Stroop: Interference condition & Inhibition & .02 & .17 & .15 & -.20 & .04 & .16 & .06 & -.07 & .06 & .24 & -.22 & .18 & .23 & .03 \\
\hline
\end{tabular}

${ }^{* *}$ correlation level of significance $\mathrm{P}<.01$; ${ }^{*}$ correlation level of significance $\mathrm{P}<.05$; PANDA, Parkinson Neuropsychometric Dementia Assessment ; MMSE, Minimental State

Examination; CERAD, Consortium for the Registry for Alzheimer's Disease (CERAD); BTA, Brief test of attention; WMS, Wechsler Memory Scale Revised; mWCST, Modified Card

Sorting Test; LPS 50+, intelligence scale Leistungsprüfsystem for subjects between 50 and 90 years of age; ${ }^{*}$ Data referred to standardized scores (e.g. Z-scores or percentile rank 
scores, indicating the patient's relative position in the norm group with a range between 0 and 100) of healthy German control subjects as published in the manuals. Data are

corrected either for age or for age and education (CERAD, TMT, mWCST). 
Figure A Correlations between physical behavior parameters.

A.

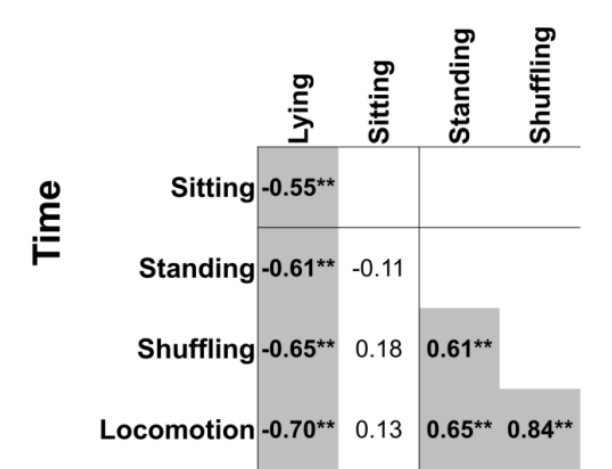

c.

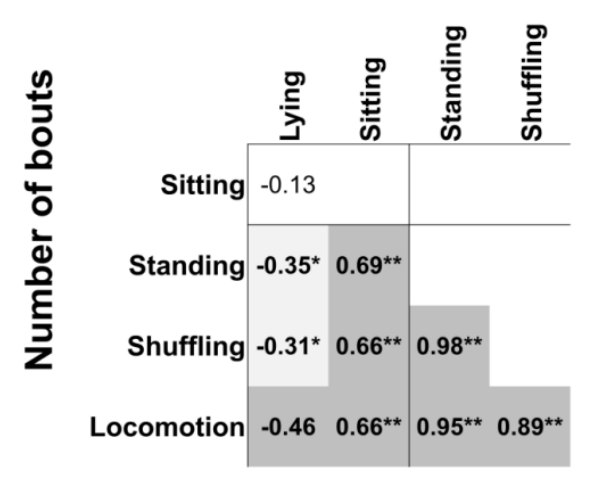

B.

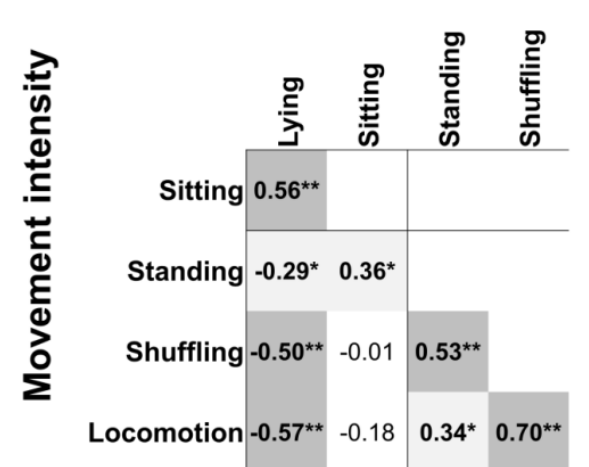

D.

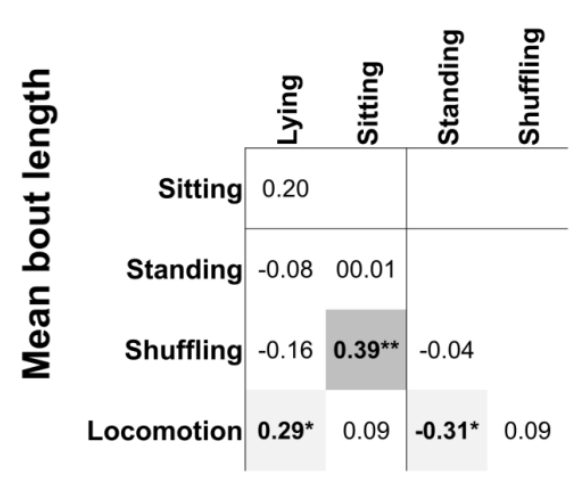

Spearman's coefficient for the parameter outcomes of Time (A), Movement Intensity (B), Number of Bouts (C) and Mean Bout length (D) between different behaviors over all study groups. ${ }^{* *}$ correlation level of significance $P<0.01$, ${ }^{*}$ correlation level of significance $P<0.05$. 